\title{
ANALISIS PEMELIHARAAN PREVENTIF AC PACKAGE PADA GERBONG KERETA PENUMPANG K1 DI DEPO 2 GERBONG KERETA BANDUNG
}

\author{
Gilang Muharam Pratama Putra1', Andri Irawan² \\ 1,2 Universitas Jenderal Achmad Yani, Cimahi Jawa Barat \\ Email: andririfki81@gmail.com
}

\begin{abstract}
This study aims to analyze the maintenance of AC Package preventive on the K1 passenger train car at Depo 2 of Bandung Rail Car. This research is a qualitative descriptive, using snowball sampling technique. Data collection techniques in this study were interviews, observation, and documentation. In this study using a validity test that is a triangulation of sources, triangulation of techniques and triangulation of time.

The results showed that in maintaining the economic life of the AC Package is still not good and still found damage to the AC Package. In the supply of technicians, equipment and supplies are still not available as specified. There are still 44 technicians needed and the equipment is still in poor condition. in this case, the AC Package preventive maintenance activities on $\mathrm{K} 1$ passenger train cars still have a lot to be repaired at Depo 2 Bandung
\end{abstract}

Keyword : Maintenance, Preventive Maintenance, AC

\section{PENDAHULUAN}

\subsection{Latar Belakang}

PT. Kereta Api Indonesia dituntut untuk mampu meningkatkan pelayanan kepada masyarakat sebagai transportasi massal dengan memberikan kenyamanan dan keamanan serta harga yang terjangkau. PT. Kereta Api Indonesia perlu meningkatkan kualitasnya yaitu dengan cara memberikan apa yang menjadi harapan para konsumennya (Puspita dan Santoso, 2018). Kualitas pelayanan yang baik juga sangat dibutuhkan oleh masyarakat dalam jasa transportasi. PT. Kereta Api Indonesia senantiasa meningkatkan fasilitas dan kualitas pelayanan untuk memberikan kenyamanan konsumen. Untuk memenuhi pelayanan pengguna jasa kereta api, baik sebagai angkutan penumpang maka PT. KAI harus terus meningkatkan pelayanan mulai dari pengadaan armada baru, perawatan rutin, perbaikan, dan lain sebagainya (Hutalang dan Bisono, 2018).

Salah satu pemeliharaan sarana dan prasarana yang bisa dilakukan oleh PT. Kereta Api Indonesia adalah dengan melakukan pemeliharaan preventif. Perawatan alat diperlukan perawatan secara preventif maupun korektif agar mampu mencapai batas umur pemakaian secara optimal. Perawatan secara preventif perlu dilakukan secara periodik terhadap setiap alat yang dimiliki, sehingga frekuensi dan biaya perawatan secara korektif dapat ditekan (Seftiawan, 2017).

Daerah Operasi II Bandung atau disingkat dengan DAOP 2 Bandung atau Daop II BD adalah salah satu daerah operasi perkeretaapian Indonesia, dibawah lingkungan kerja PT. Kereta Api Indonesia (Persero) dipimpin oleh seorang Vice President (VP) dan bertanggung jawab kepada Direksi PT. Kereta Api Indonesia.

Dalam melakukan pemeliharaan dan perawatan sarana dan prasarana dilakukan dengan pemeliharaan preventif dan pemeliharaan korektif. Hal ini ditunjang dengan kualitas sumber daya manusia yang berkompeten dibidangnya dan sistem pemeliharaan/ perawatan kereta gerbong yang terjadwal dengan baik. Pada setiap gerbong kereta terdapat beberapa kerusakan-kerusakan yang sering terjadi. Kerusakan tersebut menjadi masalah dalam pemeliharaan preventif. Kerusakan-kerusakan yang sering terjadi yaitu kerusakan pada bagian interior yang terdiri dari 
kerusakan AC, toilet, kaca jendela, kursi, pintu dan lampu dan kerusakan eksterior yaitu pada apron atau jembatan kereta pada gerbong kereta api penumpang, bagian rangka bawah dan pada bagian listrik. Pada setiap gerbong memiliki tingkatan kerusakan yang berbedabeda. Sehingga pemeliharaan dan perawatan yang dilakukan pun berbeda-beda.

AC Package pada kereta K1 digunakan setiap hari, karena untuk kenyamanan konsumen. Namun AC Package pada gerbong kereta penumpang $\mathrm{K} 1$ sudah diatur, dimana suatu suhu diruangan telah mencapai pada titik suhu yang telah ditentukan maka $A C$ tersebut secara otomatis mati baik di kereta lama maupun kereta baru. Dalam satu gerbong kereta penumpang $\mathrm{K} 1$ menggunakan dua unit AC Package. AC Package yang digunakan pada gerbong kereta penumpang terdapat perbedaan dengan AC yang digunakan dirumah atau kantor. Perbedaannya terdapat pada penempatan pada setiap komponen AC tersebut. Untuk AC Package terdapat dalam satu rangkaian di atap gerbong kereta. Sedangkan untuk $A C$ rumah atau kantoran penempatan $A C$ dan komponen $A C$ lainnya secara terpisah.

Berdasarkan uraian di atas, menunjukan isu sentral pada penelitian ini mengenai masih tingginya tingkat kerusakan pada AC Package meskipun sudah dilakukan penerapan pemeliharaan preventif. Hal tersebut bisa terjadi karena adanya hambatan dalam pemeliharaan yang dilakukan di Depo 2 Gerbong Kereta Bandung.

\subsection{Perumusan Masalah}

1. Bagaimana perencanaan pemeliharaan preventif AC Package pada gerbong kereta penumpang K1 di Depo 2 Gerbong Kereta Bandung?

2. Bagaimana pelaksanaan pemeliharaan preventif AC Package pada gerbong kereta penumpang K1 di Depo 2 Gerbong Kereta Bandung?

3. Bagaimana evaluasi pemeliharaan preventif AC Package pada gerbong kereta penumpang K1 di Depo 2 Gerbong Kereta Bandung?

\subsection{Maksud dan Tujuan Penelitian}

Tujuan yang ingin dicapai sesuai dengan identifikasi masalah yang akan diteliti dalam penelitian ini adalah untuk mengetahui:

1. Perencanaan pemeliharaan preventif $A C$ Package pada gerbong kereta penumpang K1 di Depo 2 Gerbong Kereta Bandung.

2. Pelaksanaan pemeliharaan preventif $A C$ Package pada gerbong kereta penumpang K1 di Depo 2 Gerbong Kereta Bandung.

3. Evaluasi pemeliharaan preventif $A C$ Package pada gerbong kereta penumpang K1 di Depo 2 Gerbong Kereta Bandung.

\section{TINJAUAN PUSTAKA}

\subsection{Manajemen Operasi}

Manajemen operasi merupakan salah satu dari keempat fungsi perusahaan selain pemasaran, keuangan, dan sumberdaya manusia. Manajemen operasi berkembang seiring dengan adanya inovasi dan munculnya teknologi baru. Manajemen operasi berkaitan dengan proses produksi dan kegiatan kegiatan yang mendukung lainnya.

Menurut Sumolang dkk, (2017) "Manajemen Operasional dapat diartikan sebagai rangkaian kegiatan atau aktifitas yang menciptakan nilai produk baik berupa barang maupun jasa melalui proses transformasi input menjadi output". Menurut Robin (2016) "Operations management, The transformation process that converts resources into finished goods and service".

Sedangkan Brandon (2018), "Operations and process management is the activity of managing the resources and processes that produce products and services, for internal and external customers". Dari beberapa definisi di atas maka dapat disimpulkan bahwa manajemen operasi merupakan pengelolaan sumber daya yang dimiliki perusahaan untuk menghasilkan produk baik barang maupun jasa sesuai dengan ketentuan perusahaan yang memiliki nilai tambah dan berkualitas tinggi untuk memenuhi kebutuhan dan keinginan konsumen.

Dilihat dari definisi manajemen operasional, maka manajemen operasi terbentuk atas beberapa keputusan dan aktivitas utama, yaitu keputusan dan aktivitas 
desain, transformasi dan perbaikan terusmenerus pada sistem.

Menurut Brandon, et all (2018). "There are five aspects of operations and process performance, all of which to a greater or lesser extent will affect customer satisfaction and business competitiveness

1. Quality - doing things right, providing error-free goods and services that are 'fit for their purpose'.

2. Speed - doing this fast, minimising the time between a customer asking for goods and services and the customer receiving them in full.

3. Dependability - doing things on-time, keeping the delivery promises that have been made to customers.

4. Flexibility - changing what you do or how you do it, the ability to vary or adapt the operation's activities to cope with unexpected circumstances or to give customers individual treatment, or to introduce new products or services.

5. Cost - doing things cheaply, producing goods and services at a cost that enables them to be priced appropriately for the market, while still allowing a return to the organisation (or, in a not for profit organisation, that gives good value to the tax payers or whoever is funding the operation).

\subsection{Pemeliharaan (maintenance)}

Folren, dkk (2019) mengemukakan bahwa, "Pemeliharaan preventif merupakan kegiatan pemeliharaan untuk bertujuan mencegah terjadinya kerusakan dan kemunduran fungsi bangunan baik yang dilakukan secara rutin atau dengan selang waktu tertentu". Selanjutnya menurut Lubis, dkk (2017), "Pemeliharaan preventif adalah suatu kegiatan pemeliharaan yang dilaksanakan secara terencana dan periodik dalam bentuk penjadwalan (time schedule), tujuannya untuk mengurangi kemungkinan kerusakan, gangguan dan menjaga fasilitas".

Sedangkan menurut Pralika, dkk (2018), "Kegiatan pemeliharaan yang dilakukan secara berkala dengan periode waktu tertentu pada setiap item untuk menjaga kemampuan sistem dan mencegah kegagalan sistem"

Selanjutnya menurut Sulistyo dkk (2019), "Perawatan adalah aktivitas pemeliharaan, perbaikan, penggantian, pembersihan, penyetelan, dan pemeriksaan terhadap objek yang dirawat". Berdasarkan definisi di atas, maka dapat disimpulkan pemeliharaan adalah suatu kegiatan yang dilakukan secara beruntun untuk menjaga fasilitas agar tetap berjalan sesuai fungsinya. Menurut Ali dan Kusuma (2019), ada empat jenis pemeliharaan diantaranya:

1. Preventive maintenance dapat diartikan sebagai sebuah tindakan perawatan untuk menjaga sistem atau sub-assembly agar tetap beroperasi sesuai dengan fungsinya dengan cara mempersiapkan inspeksi secara sistematik, deteksi, dan koreksi pada kerusakan yang kecil untuk mencegah terjadinya kerusakan yang lebih besar.

2. Reactive Maintenance, jenis perawatan ini juga dikenal sebagai breakdown, membenarkan apabila terjadi kerusakan.

3. Tes prediksi dan inspeksi Walaupun banyak metode yang dapat digunakan untuk menentukan jadwal PM, namun tidak ada yang valid sebelum didapatkan agerealibility characteristic dari sebuah komponen.

4. Proactive Maintenance, jenis perawatan ini membantu meningkatkan perawatan melalui tindakan seperti desain yang lebih baik, workmanship, pemasangan, penjadwalan, dan prosedur perawatan.

Pemeliharaan yang dilakukan memiliki tujuannya masing-masing. Adapun tujuan pemeliharaan menurut para ahli sebagai berikut: Menurut Haq dan Riandadari (2019), "Tujuan pemeliharaan adalah untuk memelihara kemampuan mesin atau alat dan mengendalikan biaya sehingga mesin harus dirancang dan dipelihara untuk mencapai standar mutu dan kinerja yang diharapkan. persoalan yang dihadapi oleh suatu perusahaan dalam kegiatan pemeliharaan adalah persoalan teknis dan persoalan ekonomis". 
Sedangkan menurut Lubis dkk (2017), beberapa alasan pentingnya melakukan pekerjaan pemeliharaan, antara lain:

1. Agar fasilitas dapat siap dipakai pada saat yang diperlukan.

2. Seiring dengan waktu, tentunya kondisi dari suatu fasilitas yang mengalami pemakaian, kemampuan kinerjanya lambat laun akan menurun karena tanpa pemeliharaan semua fasilitas tersebut akan melemah secara bertahap tapi pasti, sehingga tidak lagi mempunyai kemampuan kerja baik secara teknis maupun ekonomis.

3. Diharapkan akan dapat memperpanjang umur pakai dari fasilitas tersebut.

Selanjutnya menurut Jamal dkk (2018), "Pemeliharaan bertujuan untuk meningkatkan reliability, availability dan effiency, memperpanjang umur, mengurangi resiko kegagalan atau kerusakan dan memprediksi serta mengurangi lama waktu padam akibat gangguan".

Menurut Kurniawan dalam Sulistyo dkk (2019), Adapun tujuan dari perawatan, adalah sebagai berikut:

1. Meningkatkan nilai tambah produk, sehingga perusahaan dapat bersaing dipasar global.

2. Membantu para pengambil keputusan, sehingga dapat memilih solusi optimal terhadap kebijakan perawatan fasilitas industri.

3. Meningkatkan efisiensi sumber daya produksi.

4. Melakukan perencanaan terhadap perawatan preventif, sehingga memudahkan dalam proses pengontrolan aktivitas perawatan.

5. Mereduksi biaya perbaikan dan biaya yang timbul dari terhentinya proses karena permasalahan keandalan mesin.

6. Meminimasi downtime, yaitu waktu selama proses produksi terhenti (waktu menunggu) yang dapat mengganggu kontinuitas proses.
7. Mengatasi segala permasalahan, yang berkenan dengan kontinuitas aktivitas produksi.

8. Memperpanjang umur pengoperasian peralatan dan fasilitas industri.

9. Peningkatan profesionalisme personil departemen perawatan industri.

Berdasarkan pernyataan di atas, maka tujuan dari pemeliharaan yaitu menjaga fasilitas agar dapat digunakan dengan baik, sehingga memperpanjang umur ekonomis dan menekan biaya pemeliharaan.

\subsection{Pemeliharaan Preventif}

Heizer and Render (2018) menyatakan bahwa, "Preventive maintenance is a plan that involves monitoring, routine inspections, servicing, and keeping facilities in good repair".

$$
\text { Selanjutnya Farinha (2018), }
$$

"Preventive maintenance is maintenance carried out at predetermined intervals or according to prescribed criteria in order to reduce the likelihood of damage or degradation of the operation of an asset". Menurut Bustami dan Nurhazana (2018) mengemukakan: "Preventive maintenance adalah perawatan yang bertujuan untuk mencegah terjadinya kerusakan, atau cara perawatan yang direncanakan untuk pencegahan kerusakan".

Menurut Setiadi dan Runtuk (2017), "Preventive maintenance merupakan kegiatan perawatan yang dilakukan secara terjadwal dan umumnya dilakukan secara periodik". Selanjutnya menurut Siswanto (2017), "Pemeliharaan pencegahan (preventive maintenance) adalah inspeksi periodik untuk mendeteksi kondisi yang mungkin menyebabkan produksi berhenti atau berkurangnya fungsi proses mesin dikombinasikan dengan pemeliharaan untuk menghilangkan, mengendalikan, kondisi tersebut dan mengembalikan mesin ke kondisi semula atau dengan kata lain deteksi dan penanganan diri kondisi abnormal mesin sebelum kondisi tersebut menyebabkan cacat atau kerugian. Berdasarkan definisi di atas dapat disimpulkan bahwa pemeliharaan preventif adalah perawatan yang dilakukan apabila terdeteksi adanya kerusakan yang bertujuan untuk meningkatkan pelayanan jasa 
transportasi yang memberikan kenyamanan dan keamanan yang baik.

Pemeliharaan preventif ini bertujuan untuk membangun suatu sistem yang akan menemukan kegagalan potensial dan melakukan perubahan atau perbaikan yang dapat mencegah terjadinya kegagalan. Menurut Setiadi dan Runtuk (2017), "Preventive maintenance bertujuan untuk meningkatkan reliability, mencegah timbulnya kerusakan mesin secara mendadak, serta dapat mengurangi downtime mesin".

Terdapat beberapa langkah yang harus dilakukan dalam pemeliharaan preventif, diantaranya : Menurut Assauri dalam Haryono dan Susanty (2018), prosedur yang harus dilakukan adalah sebagai berikut:

1. Pemeriksaan (Inspection) yaitu tindakan yang ditujukan terhadap sistem atau mesin untuk mengetahui apakah sistem berada pada kondisi yang diinginkan

2. Servis (Service) yaitu tindakan yang bertujuan untuk menjaga kondisi suatu sistem yang biasanya telah diatur dalam buku petunjuk pemakaian sistem.

3. Penggantian komponen (replacement) yaitu tindakan penggantian komponen yang dianggap rusak atau tidak memenuhi kondisi yang diinginkan. Tindakan penggantian ini mungkin dilakukan secara mendadak atau dengan perencanaan pencegahan terlebih dahulu

4. Repair yaitu tindakan perbaikan minor yang dilakukan pada saat terjadi kerusakan kecil.

5. Overhaul yaitu tindakan perbaikan secara besar-besaran pada suatu mesin secara menyeluruh dan biasanya dilakukan di akhir periode tertentu. Overhaul termasuk dalam perawatan yang bersifat korektif.

6. Scouring yaitu kegiatan membersihkan dan perawatan yang dilakukan untuk mencegah timbulnya kerusakankerusakan yang tidak terduga dan menemukan kondisi atau keadaan yang dapat menyebabkan fasilitas produksi mengalami kerusakan pada waktu digunakan dalam proses produksi

\section{METODOLOGI PENELITIAN}

\subsection{Metode Penelitian}

Menurut Arikunto dalam Iviani dan Oktaviani (2017), "Metode penelitian adalah cara yang digunakan oleh peneliti dalam pengumpulan data penelitiannya". Metode penelitian yang digunakan dalam penelitian ini menggunakan pendekatan kualitatif dengan metode deskriptif. Menurut Levitt (2018), "The term qualitative research is used to describe a set of approaches that analyze data in the form of natural language (i.e., words) and expressions of experiences (e.g., social interactions and artistic presentations)".

Menurut Wijaya (2017), "Metode penelitian deskriptif adalah salah satu metode penelitan yang banyak digunakan pada penelitian yang bertujuan untuk menjelaskan suatu kejadian". Sedangkan Sugiyono dalam Hidayat (2017), "Analisis deskriptif adalah statistik yang digunakan untuk menganalisa data dengan cara mendeskripsikan atau menggambarkan data yang telah terkumpul sebagaimana adanya tanpa bermaksud membuat kesimpulan yang berlaku untuk umum atau generalisasi.".

\subsection{Populasi dan Sampel}

Populasi dalam penelitian merupakan wilayah yang ingin diteliti oleh penelitian. Menurut Sugiyono dalam Hidayat (2017), "Populasi adalah wilayah generalisasi yang terdiri dari obyek atau subyek yang menjadi kuantitas dan karakteristik tertentu yang ditetapkan oleh peneliti untuk dipelajari dan kemudian ditarik kesimpulannya"

Sedangkan Namawi dalam Hidayat (2017), Sehingga pada penelitian ini situasi sosial adalah Depo 2 Bandung (place) dan teknisi AC (actors) yang terlibat dalam pemeliharaan preventif (activity). Adapun pengertian sampel menurut Sugiyono dalam Hidayat (2017), "Sampel adalah bagian dari jumlah dari karakteristik yang dimiliki oleh populasi tersebut".

\subsection{Teknik Pengumpulan Data}

1. Wawancara, dalam penelitian ini jenis wawancara yang digunakan adalah wawancara terstruktur yakni pertanyaan 
yang telah direncanakan dan mengetahui informasi yang diperlukan untuk diajukan kepada informan yaitu Kepala Unit Depo 2 Gerbong Kereta Bandung, Kepala Ruas Administrasi Depo 2 Gerbong Kereta Bandung, Pengawas dan Pelaksana divisi listrik dan AC.

2. Observasi, bertujuan untuk memperoleh informasi tentang kondisi lapangan dan data-data yang berkaitan dengan pemeliharaan preventif AC Package pada gerbong kereta penumpang $\mathrm{K} 1$ yang dilakukan oleh perusahaan.

3. Dalam penelitian ini menggunakan teknik pengumpulan data dengan melakukan wawancara dan observasi, sehingga peranan dokumentasi yaitu sebagai pelengkap dan pendukung agar hasil penelitian semakin kredibel. Penelitian ini dilakukan dengan menggunakan dokumen-dokumen yang ada ditempat penelitian sebagai pelengkap data. Dokumen yang digunakan yaitu dokumen laporan pemeliharaan per tahun, workorder, dan check sheet.

\subsection{Teknik Analisis Data}

Analisis data merupakan proses mengatur urutan data, mengorganisasikan ke suatu pola, kategori dan satuan uraian dasar. Dalam penelitian ini penulis melakukan analisis data kualitatif. Data yang telah diperoleh melalui wawancara, observasi dan dokumen yang diberikan kemudian diproses dan dianalisis untuk pengembangan penelitian. Data yang telah diolah menghasilkan data yang relevan maka akan mendapatkan pemecahan dari masalah yang diteliti. Menurut Nasir dalam Sutama, dkk (2018) menjelaskan bahwa "Analisis data adalah proses mengatur urutan data, mengorganisasikannya ke dalam suatu pola, kategori, dan satuan uraian dasar".

Berikut langkah-langkah analisis menurut Miles and Huberman (2014), sebagai berikut:

1. Data Reduction (Reduksi Data), Data yang diperoleh dari lapangan jumlahnya cukup banyak, untuk itu maka perlu dicatat secara teliti dan rinci. Semakin lama peneliti ke lapangan, maka jumlah data akan semakin banyak, kompleks, dan rumit. Untuk itu perlu segera dilakukan analisis data melalui reduksi data. Mereduksi data berarti merangkum, memilih hal-hal pokok, memfokuskan pada hal-hal yang penting, dicari tema dan polanya dan tidak usah dipilih yang tidak perlu. Dengan demikian data yang telah direduksi akan memberikan gambaran yang lebih jelas, dan mempermudah peneliti untuk melakukan pengumpulan data selanjutnya.

2. Data Display (Penyajian Data), Penyajian data ini dilakukan dalam bentuk uraian singkat, bagan, hubungan antar kategori, dan sejenisnya. Dengan penyajian data, maka akan memudahkan untuk memahami apa yang terjadi, merencanakan kerja selanjutnya berdasarkan apa yang telah dipahami tersebut.

3. Conclusion Drawing / Verification , Penarikan dari kesimpulan dan verifikasi. Kesimpulan awal yang dikemukakan masih bersifat sementara, dan akan berubah bila tidak ditemukan masih bersifat sementara, dan akan berubah bila tidak ditemukan bukti-bukti yang kuat yang mendukung pada tahap pengumpulan data berikutnya. Tetapi apabila kesimpulan yang dikemukakan pada tahap awal, didukung oleh bukti-bukti yang valid dan konsisten saat peneliti kembali ke lapangan mengumpulkan data, maka kesimpulan yang dikemukakan merupakan kesimpulan yang kredibel.

\subsection{Uji Validitas dan Reliabilitas}

1. Triangulasi Sumber; Triangulasi sumber untuk menguji kredibilitas data dilakukan dengan cara mengecek data yang telah diperoleh melalui beberapa sumber. Maka diperoleh data mengenai pemeliharaan preventif AC Package pada gerbong kereta K1, faktor-faktor kerusakan dan data-data pelengkap mengenai pemeliharaan preventif. Data tersebut kemudian dianalisis oleh penulis dan dimintai kesepakatan dari ketiga sumber data. 
2. Triangulasi Teknik; Triangulasi teknik untuk menguji kredibilitas data dilakukan dengan cara mengecek data kepada sumber yang sama dengan teknik berbeda. Proses pengujian kredibilitas data pada penelitian ini yaitu dengan cara mengecek keabsahan data pemeliharaan preventif pada sumber data yang sama. Peneliti melakukan observasi langsung dalam pelaksanaan pemeliharaan preventif AC package. Peneliti juga meminta dokumen terkait pemeliharaan preventif. Contohnya dokumen Check sheet, Laporan Bulanan dan Work order.

3. Triangulasi Waktu; Waktu juga sering mempengaruhi kredibilitas data. Dalam data pengujian kredibilitas data dapat dilakukan dengan cara melakukan pengecekan dengan wawancara, observasi, atau teknik lain dalam waktu atau simulasi yang berbeda. proses pengujian kredibilitas data dilakukan dengan cara mengecek data mengenai pemeliharaan preventif dilakukan wawancara dan observasi pada waktu dan situasi yang berbeda. Dari hasil wawancara dan observasi tersebut di dapatkan informasi yang sama mengenai perencanaan, pelaksanaan pemeliharaan preventif AC Package pada gerbong kereta K1 di Depo 2 Bandung.

4. Tahapan Snowball Sampling; Dalam penelitian ini memperoleh informasi dan data mengenai premeliharaan preventif AC Package pada gerbong kereta penumpang K1 di Depo gerbong kereta Bandung menggunakan teknik snowball sampling.

\section{ANALISIS DAN PEMBAHASAN}

4.1 Pemeliharaan Preventif AC Package pada Gerbong Kereta Penumpang K1 di Depo 2 Bandung

Kegiatan pemeliharaan tersebut memiliki tujuan, yaitu untuk memungkinkan tercapainya mutu pemeliharaan, memaksimalkan umur kegunaan dari sistem, menjaga kualitas pelayanan PT Kereta Api Indonesia pada saat melakukan perjalanan. Pemeliharaan preventif merupakan pemeliharaan yang direncanakan bertujuan untuk mencegah terjadinya kerusakan.

Memungkinkan tercapainya mutu pemeliharaan dan kepuasan pelanggan melalui penyesuaian, pelayanan dan pengoperasian peralatan secara tepat. Tercapainya mutu pemeliharaan, kepuasan pelanggan, pelayanan dan pengoperasian peralatan secara tepat merupakan tujuan pemeliharaan preventif Depo 2 gerbong kereta. Pemeliharaan preventif memegang peranan yang penting dalam upaya mencegah terjadinya kerusakan pada AC Package yang digunakan. Untuk itu memerlukan biaya yang dikeluarkan tiap tahun meningkat untuk mencapai mutu pemeliharaan secara efektif agar kualitas pelayanan terjaga dan memuaskan pelanggan. Dengan adanya kegiatan pemeliharaan preventif ini maka fasilitas atau peralatan dapat digunakan sesuai dengan rencana dan tidak mengalami kerusakan selama peralatan tersebut digunakan. Untuk mencapai mutu pemeliharaan terdapat waktu pemeliharaan preventif.

Waktu pemeliharaan preventif tersebut diantaranya pemeliharaan $\mathrm{P} 1$ dengan waktu pemeliharaan selama 28 jam orang, dan pada pemeliharaan AC Package waktu pemeliharaan selama 2 jam orang. Selanjutnya waktu pemeliharaan P3 yaitu selama 49 jam orang, dengan pemeliharaan preventif AC Package waktu pemeliharaan selama 5 jam orang. Pada pemeliharaan $\mathrm{P} 6$, waktu pemeliharaannya selama 61 jam orang, khususnya pada pemeliharaan preventif AC Package selama 8 jam orang. Dan pada pemeliharaan P12 waktu pemeliharaannya selama 86 jam orang, dimana pemeliharaan preventif AC Package selama 12 jam orang.

Dalam pelaksanaan pemeliharaan preventif AC Package waktu pemeliharaannya telah sesuai dengan ketentuan yang telah ditetapkan perusahaan, dimana pada pemeliharaan P1 selama 2 jam orang, pemeliharaan P3 selama 5 jam orang, pemeliharaan P6 selama 8 jam orang dan pemeliharaan P12 selama 12 jam.

1. Memaksimalkan umur kegunaan dari sistem. Pemeliharaan preventif merupakan pemeliharaan yang terjadwal yang 
bertujuan untuk mencegah kerusakan. Apabila pemeliharaan preventif tidak dilakukan, maka secara teratur AC package yang digunakan akan mengalami kerusakan dan akan berakibat fatal sehingga mengurangi kualitas pelayanan yang diberikan oleh PT. Kereta Api Indonesia kepada pelanggan. Dampak lainnya dari tidak dilakukannya pemeliharaan preventif adalah berkurangnya umur ekonomis pada AC package. Maka dari itu, pemeliharaan preventif sangat penting dilakukan di Depo 2 Bandung.

2. Menyiapkan personel, fasilitas dan metodenya agar mampu mengerjakan tugas-tugas perawatan. Pemeliharaan mengikut sertakan pengembangan dari seluruh lintasan kegiatan yang mencakup semua kegiatan perawatan, reparasi, dan pekerjaan overhaul. Kendala yang mungkin muncul dalam perencanaan pemeliharaan dapat disebabkan berbagai aspek seperti komuikasi ketidakjelasan instruksi, kurangnya informasi maupun berbagai keterlambatan, ketidakpastian jumlah spare parts, jumlah tenaga kerja yang kurang, kualitas peralatan pemeliharaan preventif yang masih kurang baik.

3. Meningkatkan pelayanan menjadi lebih baik dalam jasa transportasi di Indonesia. Peningkatan dari pelayanan kereta api merupakan kemauan berbagai pihak, hal ini dikarenakan kereta api adalah trasportasi masal yang mampu mengangkut banyak penumpang secara bersamaan. Namun dalam kualitas pelayanan kereta api masih terdapat permasalahan yang dimana masih dinilai tidak mengalami kemajuan terutama pada keamanan, kenyamanan, kelesamatan dan keterlembatan perjalanan kereta api. Untuk mengatasi permasalahan tersebut Depo 2 Bandung melakukan perbaikan atau pemeliharaan fasilitas yang terdapat di gerbong kereta $\mathrm{K} 1$, khususnya pada $\mathrm{AC}$ Package.
4.2 Pelaksanaan

perencanaan

pemeliharaan preventif AC Package pada gerbong kereta penumpang K1 di Depo 2 Bandung

Prosedur merupakan tahap-tahap yang harus dilakukan dalam mengerjakan suatu pekerjaan. Dalam pemeliharaan preventif memiliki prosedur tertulis dalam kegiatan pemeliharaan preventif.

1. Pemeriksaan (Inspection); Pemeriksaan bisa dilakukan pemeliharaan preventif maupun pemeliharaan korektif. Pemeriksaan dilakukan pada komponenkomponen AC Package seperti komponen evaporator, compresor, condensor, dan motor blower. Pemeriksaan ini dilakukan rutin disaat melaksanakan pemeliharaan preventif, bertujuan untuk mengetahui kerusakan-kerusakan yang terjadi pada AC Package.

2. Servis (Service); Servis dilakukan apabila saat melakukan pengecekan seluruh komponen dan sistem AC Package bertujuan untuk menjaga kondisi pada sistem yang telah diterapkan di perencanaan perusahaan. Biasanya servis dilakukan pada sistem AC. Servis sistem $A C$ ini untuk mengontrol sistem-sistem yang telah ditetapkan perusahaan agar menjaga kondisi sistem AC lebih baik.

3. Penggantian komponen (Replacment); Penggantian komponen merupakan salah satu prosedur pemeliharaan preventif. Saat pengecekan dilakukan dan menemukan adanya kerusakan pada komponen AC maka dilakukan perbaikan. Kerusakan yang sering terjadi pada $A C$ Package adalah kebocoran pipa-pipa AC yang akan berdampak pada komponen lainnya seperti compresor, condensor, filter udara, dan evaporator. Apabila dari komponen tersebut rusak, maka AC Package yang digunakan harus diganti dengan AC Package yang baru.

4. Repair; Repair atau perbaikan yang dilakukan dalam pemeliharaan preventif yaitu untuk mencegah terjadinya kerusakan pada komponen agar tidak berdampak pada komponen yang lainnya. Perbaikan ini juga bisa dilakukan saat 
pemeliharaan preventif dan pemeliharaan korektif. apabila di pemeliharaan P1, P3, P6, P12 terdapat kerusakan pada AC Package maka dilakukan perbaikan.

5. Scouring; Dalam pemeliharaan preventif scouring ini penting sekali dilakukan karena untuk mencegah timbulnya kerusakan-kerusakan yang tidak terduga saat dioperasikan. Pelaksanaan scouring ini dilakukan setelah perbaikan dan pemeliharaan dilakukan dengan baik. Scouring melakukan pembersihan pada komponen dan sistem AC agar dapat berfungsi dengan baik.

\subsection{Pelaksanaan Pemeliharaan AC Package pada gerbong kereta penumpang $\mathrm{K} 1 \mathrm{di}$ Depo 2 Bandung}

Pelaksanaan tujuan pemeliharaan preventif AC Package pada gerbong kereta penumpang K1 di Depo 2 Bandung memegang peranan yang penting dalam upaya mencegah terjadinya kerusakan pada AC package yang digunakan. Untuk mencapai mutu pemeliharaan secara efektif memerlukan biaya yang dikeluarkan tiap tahun agar kualitas pelayanan terjaga dan memuaskan pelanggan. Melakukan SOP yang telah ditentukan dengan baik dan tepat. Umur ekonomis AC package yang digunakan pada kereta $\mathrm{K} 1$ adalah selama 5 tahun. Sering terjadi kerusakan pada AC package sebelum umur ekonomis $A C$ tersebut habis. Sehingga perusahaan harus mengganti $A C$ yang rusak dengan yang $A C$ yang baru.

Pemeliharaan mengikutsertakan pengembangan dari seluruh lintasan kegiatan yang mencakup semua kegiatan perawatan, reparasi, dan pemeriksaan. Kendala yang mungkin muncul dalam perencanaan pemeliharaan dapat disebabkan berbagai aspek seperti kurangnya komuniasi instruksi, kurangnya informasi maupun berbagai keterlambatan, dan ketidakpastian spare parts atau tenaga kerja yang terampil. Jumlah tenaga kerja di Depo 2 Bandung bejumlah 78 orang, baik dari divisi genset, AC dan listrik, mekanik rangka bawah dan perbaikan Namun sebagian orang dipindah tugas ke berbagai daerah di Bandung. Pada bagian AC sendiri berjumlah 5 orang untuk melakukan pemeliharaan. Keterbatasan meterial dan peralatan kerja menjadi masalah utama dalam pelaksanaan pemeliharaan preventif. Sehingga dalam pelaksanaan pemeliharaan preventif terhambat dan kereta penumpang yang seharusnya beroperasi menjadi terhenti. Kualitas pelayanan kereta api masih terdapat permasalahan yang dimana masih dinilai tidak mengalami kemajuan terutama pada keamanan, kenyamanan, keselamatan dan keterlambatan perjalanan kereta api. Untuk mengatasi permasalahan tersebut Depo 2 Bandung melakukan perbaikan atau pemeliharaan fasilitas yang terdapat di gerbong kereta K1, khususnya pada AC Package.

\subsection{Prosedur pelaksanaan pemeliharaan preventif AC Package pada gerbong kereta penumpang $\mathrm{K} 1$ di Depo 2 Bandung}

1. Pemeriksaan (Inspection); Dari pemeriksaan ini yaitu sering ditemukannya kerusakan khususnya pada bagian AC, seperti kerusakan pada kebocoran pada pipa AC. Kerusakan pada pipa AC tersebut apabila tidak dilakukan perbaikan maka akan berdampak kepada komponen lainnya.

2. Servis (Service); Servis dilakukan apabila saat melakukan pengecekan seluruh komponen dan sistem AC Package bertujuan untuk menjaga kondisi pada sistem yang telah diterapkan di perencanaan perusahaan. Servis yang dilakukan pada sistem AC baik dilakukan apabila kerusakan pada AC package telah dilakukan.

3. Penggantian komponen (Replacement) Dalam penggantian komponen $\mathrm{AC}$ masih terjadi kehambatan, karena kurangnya ketersediaan komponen $\mathrm{AC}$ inilah yang menyebabkan kereta tidak siap beroperasi. Maka dari itu dibutuhkannya persediaan komponen AC seperti persediaan compresor, condensor, filter udara dan evaporator agar tidak terjadi kehambatan dalam pemeliharaan preventif di Depo 2 Bandung. Untuk mengatasi kehambatan pemeliharaan preventif maka pengawas dan pelaksana akan meminjam 
komponen $\mathrm{AC}$ ke kereta penumpang lainnya yang sedang melakukan pemeliharaan preventif.

4. Repair; Repair atau perbaikan yang dilakukan dalam pemeliharaan preventif yaitu untuk mencegah terjadinya kerusakan pada komponen agar tidak berdampak pada komponen yang lainnya. Kerusakan yang sering terjadi adalah pada kebocoran pipa-pipa AC. Apabila kebocoran pada AC ini tidak diperbaiki maka akan berdampak pada kerusakan komponen lainnya yang akan menyebabkan $A C$ rusak dan mati sehingga harus diganti.

5. Scouring; Pelaksanaan scouring ini dilakukan setelah perbaikan dan pemeliharaan dilakukan dengan baik. Scouring melakukan pembersihan pada komponen dan sistem AC agar dapat berfungsi dengan baik. Pembersihan ini dilakukan dengan cara membersihkan komponen komponen yang kotor, sistem yang kotor sehingga kerusakan yang terjadi dapat terhindarkan. Pelaksanaan scouring masih baik dan tetap dilakukan, baik dalam pemeliharaan preventif dan pemelilharaan koretif.

\section{v. SIMPULAN DAN SARAN}

Terdapat beberapa ketidaksesuaian yang ditemukan pada pemeliharaan preventif AC package pada gerbong kereta penumpang $\mathrm{K} 1$ diantaranya adalah kurang memaksimalkan umur ekonomis, dimana masih terjadi kerusakan pada AC package yang mengakibatkan mengurangi umur ekonomis $A C$ tersebut, kurangnya ketersediaan tenaga kerja khususnya pada bagian AC \&listrik dimana tenaga kerja berjumlah 5 orang, dan kurangnya ketersediaan peralatan dan komponen $\mathrm{AC}$ yang dibutuhkan sehingga mempengaruhi kinerja pemeliharaan preventif di Depo 2 Bandung.

Dengan adanya hal tersebut yang masih kurang dan belum maksimal maka menjadi pertimbangan perusahaan untuk melakukan evaluasi. Evaluasi dimaksudkan untuk memperbaiki kinerja pemeliharaan khususnya pemeliharaan preventif AC Package pada gerbong kereta penumpang K1 di Depo 2 Bandung.

\subsection{Saran}

1. Penambahan tenaga kerja khusunya pada bagian AC\&listrik agar pelaksanaan pemeliharaan preventif dapat dilakukan secara efektif dan efisien serta menambah ketersediaan peralatan dan komponen $\mathrm{AC}$ khususnya AC Package pemeliharaan harus tersedia sehingga tidak terjadi hambatan dalam pemeliharaan preventif AC Package.

2. Membuat safety stock komponen AC agar dalam pemeliharaan $A C$ dilakukan dengan efektif dan efisien.

3. Pengunaan alat bantu analisis berupa fishbone diagrams pada dokumentasi faktor-faktor kerusakan. Dengan adanya fishbone diagrams akan memudahkan faktor yang menyebabkan kerusakan sehingga bisa dikurangi. Fishbone diagrams mempermudah untuk menemukan dan melihat faktor kerusakan yang paling banyak terjadi dalam pemeliharaan.

Berikut adalah contoh diagram fishbone yang dibuat oleh penulis dalam pemeliharaan preventif AC Package: 


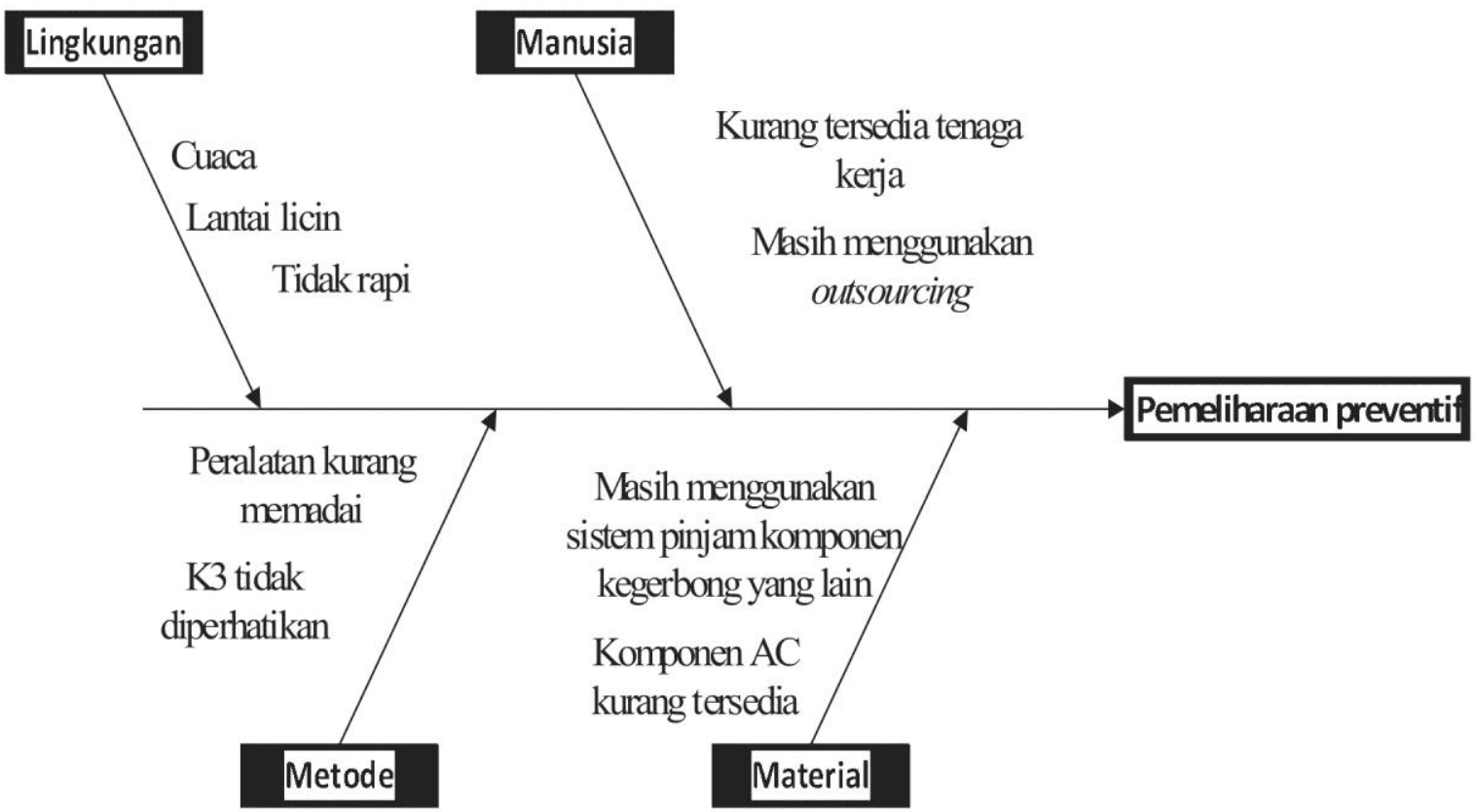

\section{DAFTAR PUSTAKA}

Ali, N., \& Kusuma, A. (2019). Penjadwalan Preventif Maintenance Jurnal Teknik Waktu Volume 17 Nomor 01 - Januari 2019 - Issn: 1412: 1867. Teknik, 17.Andreacchio, M., Bekrar, A., Benmansour,

Anjani, K., Muliati, L., Studi, P., Administrasi, M., Sekretari, A., \& Insani, B. (2016). Penerapan Seven Tools Pemeliaharaan Pada Mesin Press Keramik Pada PT Perkasa Primarindo Tambun. Mahasiswa Bina Insani, 6919, 50-62.

Bustami, \& Nurhazana. (2018). Pemodelan Kerusakan Mesin Bubut Untuk Estimasi Banyaknya Jumlah Kerusakan Dan Estimasi Biaya Perawatan Mesin Bubut Dengan Memperhatikan Faktor Inflasi Ditinjau Carnero, M. C., \& Gómez, A. (2018). Optimization Of Maintenance In Production And Storage Systems For Domestic Water. Water Resources Management, 32(1), 359-380. Https://Doi.Org/10.1007/S11269-0171815-2

David. (2018). Pengaruh E-Service Quality Terhadap Loyalitas Pelanggan Melalui Kepuasan Pelanggan Pada Transportasi Online Grab. Agora, 6(2). Https://Doi.Org/10.1057/978-1-137-59943-8
García-Alcaraz, J. L., \& Oropesa-Vento, M. (2017). Kaizen Planning , Implementing And Controlling. Switzerland: Springer International Publishing Ag. Https://Doi.Org /10.1007/978-3-31947747-3 Library

Haq, M. I., \& Riandadari, D. (2019). Penentuan Penjadwalan Preventive Maintenance Pada Komponen Mesin Callender Di PT . Karet Ngagel Surabaya Wira Jatim Dyah Riandadari. JPTM, 09, 8-16.

Haryono, L., \& Susanty, A. (2017). Penerapan Total Productive Maintenance Dengan Pendekatan Overall Equipment Effectiveness ( OEE ) Dan Penentuan Kebijakan Maintenance Pada Mesin Ring Frame Divisi Spinning I Di PT Pisma Putra Textile. Industri Engineering, 1-10.

Heizer, J., Render, B., \& Munson, C. (2017). Principles Of Operations Management Sustainability And Supply Chain Management (Tenth Edit). London: Pearson Education Limited.

Hidayat, R. (2017). Dampak Uang Servis Terhadap Semangat Kerja Karyawan Pada Perusahaan Daerah ( PD ) Hotel Swarna Dwipa Palembang. IImiah Ekonomi Global Masa Kini, 8(03), 3744. 
Hutalang, K. F., Bisono, R. M., \& Kediri, P. (2018). Perawatan Overheadcrane 5 Ton Di UPT. Balai Yasa Surabaya Gubeng Jawa Timur. Teknik Mesin, 7, 37-43.

Irviani, R., \& Oktaviana, R. (2017). Aplikasi Perpustakaan Pada SMAN1 Kelumbayan Barat

Jaya Mitra Sukses Pekanbaru Beno. IImu Komputer Dan Bisnis, 9, 1832-1863.

Ji, G., Wu, W., Zhang, B., \& Sun, H. (2016). Transient Outage Model Considering Corrective And Kaming, P. F., \& Ervianto, W. I. (2019). Model Pemeliharaan Infrastruktur Embung Berbasis Biaya Katrine, D., \& Harini, C. (2017). The Analysis Of Effect of Sense, Feel, Think, Act, And Relate As The Experiential Marketing Variables To Customer Loyalty Of Andelir Hotel Semarang, 1(September), 77-84. Https://Doi.Org/10.24961/J.Tek.Ind.Pert . 2017.27.2.141

Levitt, H. M., Bamberg, M., Creswell, J. W., Frost, D. M., Josselson, R., \& SuárezOrozco, C. (2018). Journal Article Reporting Standards For Qualitative Primary, Qualitative Meta-Analytic, And Mixed Methods Research In Psychology: The Apa Publications And Communications Board Task Force Report. American Psychologist, 73(1), 26-46. Https://Doi.Org/10.1037/Amp0000151

Liao, B., Tseng, N., \& Li, Z. (2018). Exposure Assessment Of Process By-Product Nanoparticles Released During The Preventive Maintenance of Semiconductor Fabrication Facilities. Nanopart Res, 20:203.

Lin, X., \& Chen, T. (2018). A Qualitative Approach For The Elderly' S Needs In Service Robots Design, 67-72. Https://Doi.Org/10.1145/3208833.3208 846

Lubis, M. A., Murni, I., \& Arfansyah, M. H. (2017). Pengaruh Penerapan Sistem Informasi Pemeliharaan Peralatan Dan Mesin Kantor Pada Efisiensi Jurnal
Edik Informatika. Jurnal Edik Informatika, 3, 8-17.

Mahdavi, M., Monsef, H., \& Romero, R. (2017). Reliability Effects Of Maintenance On Tnep Considering Preventive And Corrective Repairs. IEEE Transactions On Power Systems, 32(5), 3768-3781. Https://Doi.Org/10.1109/Tpwrs.2016.26 40178

Maulida, D., Kalalinggi, R., \& Dyastari, L. (2018). Rencana Strategi (Renstra) Dadan Perencanaan , Penelitian , Dan Pengembangan Prasarana Tata Ruang Di Kota Bontang. IImu Pemerintahan, 6(1), 399-410.

Miles, M., Huberman, M., \& Saldana, J. (2014). Qualitative Data Analysis. European Journal Of Science Education (Vol. 1). Https://Doi.Org/10.1080/014052879001 0406

Ningrum, S. W., Muchsin, S., \& Widodo, R. P. (2019). Evaluasi Kinerja Pelayanan Dinas Perhubungan Dalam Bidang Transportasi Umum Perkotaan ( Studi Pada Dinas Perhubungan Kota Malang Provinsi Jawa Timur ) Issn 2302-8432. Jurnal Respon Publik, 13(2), 53-61.

Prahmawati, E., Pratiwi, S., \& Hermawan, W. (2018). Optimasi Sistem Penunjang Keputusan Untuk Pemeliharaan Mesin Produksi Benih Padi Di PT Sang Hyang Seri Optimization. Keteknikan Pertanian, 6.

Prihastono, E., \& Prakoso, B. (2017). Perawatan Preventif Untuk Mempertahankan Utilitas Performance Pada Mesin Cooling Tower Di CV.Arhu Tapselindo Bandung. Dinamika Teknik, 10, 17-27.

Puspita, R. M., Santoso, S., Puspita, R. M., Santoso, S., Kristen, U., \& Wacana, D. (2018). Pengaruh Kualitas Pelayanan Dan Fasilitas Pendukung Terhadap Kepuasan Pelanggan Stasiun Lempuyangan Yogyakarta. Ekonomi Dan Bisnis, 13(1), 69-80.

Ramadhani, R. B., Widiyanti, \& Solichin. (2017). Manajemen Pemeliharaan Dan Perbaikan Pada Bengkel. Teknik Mesin, 80-90. 
Rizvi, W., Rai, A. S. D., Pawar, R., \& Tripathi, A. (2018). Preventive Maintenance Procedures For Improving Plant Efficiency: A Review, (5), 23-27.

Seftiawan. (2017). Penyediaan Dan Pemeliharaan Sarana Dan Prasarana Pariwisata Oleh Dinas Kebudayaan Pariwisata Pemuda Dan Olahraga Kabupaten Kuantan Singingi Tahun 2013-2014. Fisip, 4.

Sekaran, U., \& Bougie, R. (2017). Metode Penelitian Untuk Bisnis (6th Ed.). Salemba Empat.

Slack, N., \& Lewis, M. (2017). Operations Strategy. (Pearson Mission, Ed.) (Fifth Edit). New York.

Sugiyono. (2018). Metode Penelitian Kuantitatif, Kualitatif, Dan R\&D. Bandung: Alfabeta.

Suharti, \& Hasyimah, R. (2017). Analisis Perencanaan Pelaksanaan Dan Pengawasan Dalam Pengelolaan Keuangan Daerah Pada Dinas Kesehatan Kota Pekanbaru Tahun 2012-2014 Suharti, 121-129.

Sulistyo, A. B., \& Zakaria, T. (2019). Analisis Overall Equipment Effectiveness Mesin Vertical Roller Mill ( VRM ). Intent, 2(1).

Sumolang, D. N., Mananeke, L., \& Wenas, R. S. (2017). Analisis Penanganan Produk Fresh Food Pada PT. Midi Utama Indonesia.Tbk Cabang Manado. Jurnal Emba, 5(2), 418-426.

Sutama, I. N., Sutanty, M., \& Maulana, B. (2018). Analisis Pengaruh Penyerapan Tenaga Kerja Terhadap Pendapatan
Usaha Pengepul Ikan Tahun 2016 ( Studi Kasus Pada UD . Usaha Mina Desa Labuan Sumbawa Kecamatan Labuan Badas). Jurnal Ekonomi Dan Bisnis, 15(1), 32-43. Retrieved From Https://Journal.Unimal.Ac.ld /Emabis/Article/Niew/279

Wibowo, H., Sidiq, A., \& Ariyanto. (2018). Penjadwalan Perawatan Komponen Kritis Dengan Pendekatan. Jurnal IImiah Teknik Industri, 6(2), 79-87.

Wijaya, H. O. L. (2017). Perancangan Aplikasi Pemetaan Lokasi Usaha Kecil Menengah (UKM) Di Kota Lubuklinggau Berbasis Goegraphic Information System (GIS) Dan Location Based Service (LBS). Jurnal Teknik Informatika Dan Sistem Informasi, 3(2), 85-94.

Www.Bumn.Go.Id. (2017). Kereta Api, Lokomotif Pembangunan Transportasi Indonesia. Retrieved From Http://Bumn.Go.Id/Keretaapi/Berita/0Kereta-Api-Lokomotif-PembangunanTransportasi-Indonesia

Yanti, S., Idris, I., Hermawan, I., \& Ibrahim. (2018). Estimasi Waktu Perawatan Preventive Mesin. Teknovasi, 05, 5465.

Zoellner, J., \& Harris, J. E. (2017). MixedMethods Research In Nutrition And Dietetics. Journal Of The Academy Of Nutrition And Dietetics, 117(5), 683697.

Https://Doi.Org/10.1016/J.Jand.2017.0 1.018 